\title{
Direct and Indirect Effects of PM on the Cardiovascular System
}

\author{
Timothy D. Nelin ${ }^{1,}$, Allan M. Joseph ${ }^{1,{ }^{*}}$, Matthew W. Gorr ${ }^{1}$, and Loren E. Wold ${ }^{1,2,3}$ \\ ${ }^{1}$ Center for Cardiovascular and Pulmonary Research, The Research Institute at Nationwide \\ Children's Hospital, Columbus, Ohio USA \\ ${ }^{2}$ Department of Pediatrics, The Ohio State University College of Medicine, Columbus, Ohio USA \\ ${ }^{3}$ Department of Physiology and Cell Biology, The Ohio State University College of Medicine, \\ Columbus, Ohio USA
}

\begin{abstract}
Human exposure to particulate matter (PM) elicits a variety of responses on the cardiovascular system through both direct and indirect pathways. Indirect effects of PM on the cardiovascular system are mediated through the autonomic nervous system, which controls heart rate variability, and inflammatory responses, which augment acute cardiovascular events and atherosclerosis. Recent research demonstrates that PM also affects the cardiovascular system directly by entry into the systemic circulation. This process causes myocardial dysfunction through mechanisms of reactive oxygen species production, calcium ion interference, and vascular dysfunction. In this review, we will present key evidence in both the direct and indirect pathways, suggest clinical applications of the current literature, and recommend directions for future research.
\end{abstract}

\section{Keywords}

particulate matter; cardiovascular dysfunction; air pollution; inflammation; reactive oxygen species

\section{Introduction}

Particulate matter (PM) exposure is one of the most pressing issues in modern-day public health, particularly in relation to the effects on the cardiovascular system. Human exposure to PM has been specifically linked to a number of cardiovascular conditions (Brook et al., 2010; Sun et al., 2010), including myocardial infarction (Peters et al., 2001; Sullivan et al., 2005), hypertension (Ibad-Mulli et al., 2001; Choi et al., 2007), atherosclerosis (Allen et al., 2009; Araujo and Nel, 2009), heart rate variability (Cavallari et al., 2008; Whitsel et al., 2009), thrombosis (Baccerelli et al., 2008; Emmerechts et al., 2010), and coronary heart disease (Puett et al., 2009; Simkhovich et al., 2009), all occurring due to either direct or indirect mechanisms of action. The number of people affected by air pollution is continuously increasing as countries thrive on heavy industrialization. PM is one of the

(C) 2011 Elsevier Ireland Ltd. All rights reserved.

Corresponding author: Loren E. Wold, PhD, FAHA, Center for Cardiovascular and Pulmonary Research, The Research Institute at Nationwide Children's Hospital, Department of Pediatrics/Physiology and Cell Biology, The Ohio State University, 700 Children's Drive W321, Columbus, OH 43205, Loren.Wold@ nationwidechildrens.org, Phone: 614-355-3015, Fax: 614-722-4881.

these authors contributed equally to the manuscript

Publisher's Disclaimer: This is a PDF file of an unedited manuscript that has been accepted for publication. As a service to our customers we are providing this early version of the manuscript. The manuscript will undergo copyediting, typesetting, and review of the resulting proof before it is published in its final citable form. Please note that during the production process errors may be discovered which could affect the content, and all legal disclaimers that apply to the journal pertain. 
major constituents of air pollution and evidence continues to grow citing PM as one of the most harmful pollutants. Numerous sources, including combustion engines, industrial products, and natural causes such as forest fires produce PM and PM-related co-pollutants.

PM is divided into three categories, including: coarse, fine and ultrafine particles. Coarse particles have a diameter of 2.5-10 $\mu \mathrm{m}$, however they will be referred to as $\mathrm{PM}_{2.5-10}$. Fine particles $\left(\mathrm{PM}_{2.5}\right)$ have a diameter less than $2.5 \mu \mathrm{m}$, and ultrafine particles - often referred to as UFPs - have a diameter of less than $0.1 \mu \mathrm{m}\left(\mathrm{PM}_{0.1}\right)$ (Brook et al., 2010). $\mathrm{PM}_{2.5}$ and $\mathrm{PM}_{0.1}$ are of special interest to the scientific community, as these particles have the capability to be inhaled deeply into the lungs and be deposited on the alveoli to produce a host of deleterious effects (Kampa and Castanas, 2008). In addition, UFPs can aggregate to form particles in the size range of $\mathrm{PM}_{2.5}$. Understanding the mechanisms that trigger these effects is useful at the clinical level, and is best done by separating them into two general pathways: direct and indirect, as these two general divisions are evident within the literature. Indirect pathways were originally thought to be the only mechanism whereby particle exposure to the respiratory system caused a release of an inflammatory/cytokine milieu that circulated through the bloodstream to affect the heart. More recent data, including from our group (Wold et al., 2006), have shown that $\mathrm{PM}$ - especially $\mathrm{PM}_{2.5}$ and $\mathrm{PM}_{0.1}$ - can cross into the pulmonary and systemic circulations directly affecting the heart and blood vessels. In this review, we will delineate the key experiments within both the direct and indirect pathways, suggest clinical applications of the current literature, and recommend directions for future research.

\section{Indirect Effects}

\subsection{Epidemiological Overview}

Extensive epidemiological research has demonstrated that multiple, acute cardiovascular events are associated with exposure to increased levels of both $\mathrm{PM}_{2.5}$ and $\mathrm{PM}_{0.1}$ (Pope et al., 2004) To further explore these effects, most studies have concentrated on the indirect effects of PM exposure on the cardiovascular system (see Figure 1 for a schematic of these effects). These indirect effects can be further categorized into responses of the nervous system and inflammatory responses. Studies have also shown that patients with high risks of developing cardiovascular disease tend to consume tobacco, have high levels of LDL cholesterol, high blood pressure, obesity, physical inactivity, or a poor diet (Yusuf et al., 2001).

\subsection{Nervous System and Hypertension}

The autonomic nervous system (ANS) plays a large role in controlling heart rate, specifically heart rate variability (HRV; variation of the time interval between heart beats). $\mathrm{HRV}$ is necessary for proper cardiovascular function, as cardiac output varies in response to signals from various parts of the ANS. When a decrease in HRV exists, the heart rate cannot adjust in response to external signals, potentially leading to myocardial infarction (MI). Although relatively little is known in regards to specific exposure pathways, $\mathrm{PM}_{2.5}$ has been shown to affect HRV, suggesting that exposure to PM is associated with ANS function (Watkinson et al., 2001). Multiple features of the central nervous system (CNS) are also theorized to play a role in regulating cardiovascular activity (Bagate et al., 2004). Certain features of the CNS combine with the ANS to indirectly elicit a cardiovascular response to PM exposure. Hypotheses of how the ANS mediates heart rate variability include repression of $\beta$-adrenergic signaling pathways and renin-angiotensin feedback systems. Exposure to PM can decrease vagal tone, leading to a cascade of events including release of cytokines and other mediators, subsequently the release of inflammatory markers and decreased HRV (Carr and Undem, 2001). 
Mechanisms in which PM exposure affects the cardiovascular system through the ANS have been examined. Ibad-Mulli et al. (Ibad-Mulli et al., 2001) proposed that PM exposure alters heart rate control by the ANS through an increase in systolic blood pressure. This altered control by the ANS could be caused by PM that stimulates neurons in the pulmonary epithelium and alters the effects of the ANS on the vasculature, altering HRV and ultimately increasing heart rate (Pope III et al., 2000). Wilker et al. (Wilker et al., 2009) demonstrated that inositol 1,4,5-triphosphate receptor, type 2 (ITPR2) matrix metalloproteinase (MMP1), an enzyme used for calcium ion binding, may be responsible for angiotensin blockade in the renin-angiotensin pathway. This blockade is activated following chronic exposure to PM, leading to vasoconstriction, and consequently increasing blood pressure. Auchincloss et al. (Auchincloss et al., 2008) recently observed an increase in blood pressure in response to PM exposure. Increased blood pressure most likely occurred as a side-effect of the inability to regulate blood pressure, further emphasizing the role of the ANS in response to PM exposure.

In one study, hypertensive rats exposed to ambient $\mathrm{PM}_{2.5}$ took longer to return to normal cardiovascular function than hypertensive rats exposed to filtered air. Normal function can be defined by heart rate, neutrophil levels and lymphocyte levels in peripheral blood measured prior to exposure (Gordon et al., 1999). Increasing phenylephrine levels stimulated superoxide production, relaxation to the Rho-kinase inhibitor Y-27632 and an increase in Rho-kinase-1 mRNA levels; this accumulation of events promoted aortic vasoconstriction. These findings correlate with the fact that $\mathrm{PM}_{2.5}$ exacerbates the effects of hypertension mediated through the Rho/ROCK pathway (Sun et al., 2008a), involved in the regulaion of vascular smooth muscle tone (Shimokawa, 2005).

\subsection{Inflammatory responses}

An inflammatory response is clearly present following exposure to PM. The inflammatory response caused by PM can augment atherosclerotic progression, which is a cause of many cardiovascular diseases including MI and other acute coronary syndromes (Suwa et al., 2002). It has been proposed that as PM is inhaled, it enters the lung and deposits on the alveoli and produces an inflammatory response marked by the release of both inflammatory and prothrombotic cytokines into the circulation (Mills et al., 2008). A multitude of research into the inflammatory effects of PM exposure exists, including a study demonstrating that diesel exhaust particles (DEP) significantly increased the production of the inflammatory factors IL-8 and GM-CSF in DEP-treated human nasal epithelial cells (HNECs) and human mucosal microvascular endothelial cells (HMMECs) compared to untreated cells (Terada et al., 1999). A more recent study by Suwa et al. (Suwa et al., 2002) supported these hypotheses by demonstrating that atherosclerotic effects are indirectly induced in rabbits as PM enters the lungs and triggers an inflammatory cascade. Sun et al. (Sun et al., 2008b) demonstrated that mice exposed to ambient $\mathrm{PM}_{2.5}$ exhibited increased cholesterol levels, plaque burden and area, inducible nitric oxide synthase (NOS) content, lipid content, reactive oxygen species formation, tissue factor (TF) expression, and macrophage infiltration in vascular tissue. These findings indicate that $\mathrm{PM}_{2.5}$ exposure has a negative effect on the vasculature by altering vasomotor tone, inducing inflammation and ultimately augmenting atherosclerotic progression.

The link between PM and cardiovascular disease is not new, however the mechanisms whereby this association exists remain to be fully examined. Early theories suggested that pulmonary inflammation caused by PM entering the lungs and depositing on the alveoli, increasing blood coagulability and fibrinogen levels. These changes could activate various clotting factors, indirectly leading to MI (Mills et al., 2008; Seaton et al., 1995). Many independent studies have demonstrated a strong correlation between the presence of inflammatory and thrombotic markers, and the risk of cardiovascular disease (Yarnell et al., 
2005). Ghio et al. (Ghio et al., 2000) showed that exposure to concentrated ambient air particles is related to inflammation in healthy humans. Other effects on the vasculature include production of inflammatory cytokines such as GM-CSF, IL-1, IL-6, and TNF- $\alpha$ and their association with alveolar macrophage stimulation by exposure to PM (Van Eeden et al., 2001). These cytokines can enter into the circulatory system, initiating a cascade of systemic inflammatory events (Ishii et al., 2005). Acute cardiovascular events as well as development of atherosclerosis are consequences of these inflammatory events.

\subsection{Time Course}

Although early studies concentrated more on the mechanistic pathways of the cardiovascular response to PM, many recent studies have begun to focus on the time course of PM effects. Epidemiological studies have examined the time course related to impaired heart rate variability (HRV) and PM exposure. He et al. (He et al., 2010) concluded that exposure to $\mathrm{PM}_{2.5}$ elicits a cardiovascular response in the form of altered HRV most prominently 4-6 hours post-exposure. Additionally, Tamagawa et al, (Tamagawa et al., 2008) showed that exposure to $\mathrm{PM}_{10}$ provoked a sustained inflammatory response indicated by a decrease in macrophage and monocyte levels in the tissue. The rabbits exposed twice a week to $\mathrm{PM}_{10}$ exhibited an inflammatory response in the lungs over a 4 week period, while the control animals exposed to a saline solution twice a week exhibited normal cardiovascular function.

The indirect effects of PM exposure were further demonstrated by a number of studies that demonstrated an innate, biphasic time course in response to PM exposure. (Cavallari et al., 2008) demonstrated that exposure to high levels of ambient particles elicited a cardiovascular response in multiple phases, including a response at three hours following exposure, followed by a response at 9-13 hours after exposure, demonstrating a biphasic response. In a separate study examining the effects of PM in hypertensive rats, deleterious effects were noticed as long as 24 hours following exposure (Gerlofs-Nijland et al., 2005). This delayed time response may be attributed to the indirect mechanisms of response to PM exposure, requiring a longer time course to transpire compared to the mechanisms of direct action discussed in the next section. Epidemiological studies exposing both young and elderly participants to concentrated ambient particulates (CAPs) demonstrate no immediate changes in HRV, measured five hours post-exposure (Scharrer et al., 2007). As demonstrated above, the indirect effects of PM exposure can ultimately result in atherosclerosis or cardiovascular disease. The two major pathways can be subdivided into the nervous system response and the inflammatory response. The time course of these indirect pathways is usually the second phase of a bi-phasic response occurring up to 24 hours post-exposure.

\section{Direct Effects}

\section{1 Particle translocation into the systemic circulation}

The direct effects of PM on non-pulmonary cells have been hypothesized for years, however little evidence has shown that particles could enter the systemic circulation and directly affect cells outside of the alveoli. The first such evidence was published in 2001, when Nemmar et al. (Nemmar et al., 2001) demonstrated that UFPs could in fact cross into the pulmonary circulation, as well as the systemic circulation. This finding was quickly validated (Nemmar et al., 2002), and it is now well-accepted that $\mathrm{PM}_{0.1}$ and $\mathrm{PM}_{2.5}$ can enter the systemic circulation and therefore affect the heart and vasculature in a number of mammals, including humans (see Figure 1 for further understanding of the interactions between indirect and direct PM effects). Additionally, Shimada et al. (Shimada et al., 2006) demonstrated that $\mathrm{PM}_{0.1}$ and $\mathrm{PM}_{2.5}$ enter the circulation through a gap formed between alveolar epithelial cells. On the other hand, $\mathrm{PM}_{2.5-10}$ particles are unlikely to enter the 
systemic circulation due to their size and generally affect the cardiovascular system only via indirect pathways. Blood levels of UFPs have been observed to peak 10-20 minutes following exposure, while UFPs can persist in the circulation for up to an hour following exposure (Nemmar et al., 2002).

\subsection{Mechanisms of the direct effects of particulates}

3.2.1 Reactive oxygen species-Mechanisms by which PM exposure causes direct cardiovascular dysfunction are still in debate, however mounting evidence suggests that reactive oxygen species (ROS) play a key role in the development of cardiac dysfunction. Bai et al. (Bai et al., 2001) first established the role of ROS in PM-induced vascular cytotoxicity by demonstrating that antioxidant treatment in vitro ameliorated the damaging effects of DEP on vascular endothelial cells. ROS were implicated in PM-induced cardiac myocycte dysfunction by the same method (Okayama et al., 2006; Zuo et al., 2011).

Bai et al. (Bai et al., 2001) specifically identified hydrogen peroxide and superoxide production as central to the cytotoxic effects of PM. These species are not contained in the particles themselves, rather, organic hydrocarbons and transition metals catalyze reactions that produce ROS (Yergey and Risby, 1982). For example, the introduction of transition metals into tissue subsequently generates Fenton reactions, which then result in hydrogen peroxide radicals (Donaldson et al., 2001). These studies clearly demonstrate that ROS are directly involved in the negative effects of PM. In addition, hydrogen peroxide has also been shown to affect calcium release from the sarcoplasmic reticulum (Boraso and Williams, 1994), a process further detailed in the following section. These studies are an important step in examining the mechanism in which cells are insulted by PM, but are not fully significant without the knowledge of the concentration and composition of PM when it enters the bloodstream.

3.2.2 Ion channel interference-Particulate matter can directly affect cardiovascular function by interacting with ion channels, which are especially important in myocardial cells. $\mathrm{Ca}^{2+}$ is vitally important to cardiomyocyte function, as it is essential to excitationcontraction coupling and regulation of contractile strength (Louch et al., 2002). $\mathrm{Ca}^{2+}$ imbalances have been shown to lead to myocardial dysfunction, including arrhythmias (Keurs and Boyden, 2007) and contractile dysfunction (Morgan, 1991). PM may affect calcium regulation by producing peroxides, which have been shown to modify thiol groups in regulatory proteins such as the $\mathrm{Na}^{+}-\mathrm{Ca}^{2+}$ exchange protein (Coetzee et al., 1994) and Ltype $\mathrm{Ca}^{2+}$ channel protein (Chiamvimonvat et al., 1995). Antimony and heavy metals have been implicated as the constituents of PM responsible for this effect (Abramson et al., 1983).

In addition to modifying membrane-bound proteins, chemicals absorbed onto the surface of PM can affect the mitochondrial permeability transition pore (MTP) and cause heavy mitochondrial damage resulting in cardiac dysfunction (Xia et al., 2004). Oxidative stress and increased $\mathrm{Ca}^{2+}$ levels open the MTP, which causes a host of deleterious effects within the mitochondria, including membrane rupture, cytochrome $c$ release, inhibition of oxidative phosphorylation, and mitochondrial swelling (Bernardi, 1999).

\subsection{Vascular dysfunction}

PM that has translocated into the systemic circulation can also negatively impact vascular function through stimulation of atherosclerosis and thrombosis. PM exposure has been associated with arterial vasoconstriction, most likely by disrupting endothelial vasodilation and endogenous fibrinolysis through reactive oxygen species (Mills et al., 2005). In addition, PM inhibits nitric oxide synthase activity, thereby preventing the release of the vasodilator nitric oxide into the bloodstream, causing vasoconstriction (Muto et al., 1996). 
Disrupted fibrinolysis and vasodilation, in turn, can lead to atherosclerosis (Davignon and Ganz, 2004).

Another clinically relevant feature of the vascular effects of PM is the stimulation of thrombosis. UFPs that enter the systemic circulation promote clot formation in a short timeframe (within one hour), while pulmonary inflammation promotes thrombosis in a longer timeframe since the effects persist beyond the exposure itself (Nemmar et al., 2003a). In vivo experiments in a hamster model of thrombosis suggest a dosedependent effect of PM on clot formation in both arteries and veins, confirmed in vitro as DEP in hamster sera promote clot formation by platelet activation (Nemmar et al., 2003b). While most research regarding thrombosis promotion has focused on pulmonary inflammation, it is plausible that platelet activation is also present after particles translocate into the systemic circulation; more research is urgently needed in this area as the short-term prothrombotic effects may play key roles in triggering sudden cardiac events, including myocardial infarctions (Vermylen et al., 2005).

\subsection{Time courses}

Tc-labeled carbon particles can persist in the systemic circulation for up to one hour (Nemmar et al., 2002), with inferences that PM too can persist in the systemic circulation. This, however, does not limit the time course of direct insults on the heart in the short term. $\mathrm{PM}$ used in a study that observed a one-hour exposure to $\mathrm{PM}_{0.1}$ used synthetic analogues of pollutants (Nemmar et al., 2002). These particles did not carry absorbed organic compounds on their surface that could be transferred into the cell. For example, quinones and aromatics have been implicated in PM-induced mitochondrial dysfunction and are often carried on the surface of individual particles (Xia et al., 2004). Oxidant-generating capabilities of direct exposure to PM, however, could plausibly decrease after one hour as the transition metals that catalyze the Fenton reactions leave the circulation with the PM.

The time course of vascular effects is clearly characterized, as detailed above. Particles are acutely prothrombotic during the short-term and have been implicated in destabilization of atherosclerotic plaques, which in turn leads to an increased incidence of MI. This hypothesis is in line with the established association between high-pollution days and the increased incidence of acute cardiovascular events such as myocardial infarction (Tofler and Muller, 2006).

\section{Active Lines of Research}

Many studies have examined the effects of PM on the cardiovascular system, showing a clear correlation between PM exposure and multiple cardiovascular conditions, with current research focusing on the pathology of these conditions. Many of these studies have focused on the indirect effects of PM on the cardiovascular system, while less is known of the mechanisms of the direct pathways, including ROS, ion channel interference, and vascular dysfunction. Future studies should focus on the effects of UFPs and the ability of PM to enter the bloodstream and affect cardiovascular activity directly, as the direct pathways are poorly characterized but important in triggering severe cardiovascular events (Vermylen et al., 2005). The processes involved in PM entering the bloodstream are of great importance, as the chemical concentrations and composition of PM need to be determined. Studies that examine direct cellular insult on cells are not significant unless they are treated with the correct composition and concentration of PM that is observed in the bloodstream.

Fewer studies have surveyed the time course of these indirect and direct effects of PM. Future studies should focus on the time period of response, as it is clear there is a biphasic response consisting of early and delayed responses. In particular, the response seems to 
continue, even 14 hours post-exposure (Cavallari et al., 2008). Thus, research should monitor the response over a time period ranging from 24 hours to multiple days postexposure, determining the long term effects of PM exposure. Finally, there is an incomplete understanding of the effects of chronic or long-term exposure to PM; future studies should elucidate how the effects of long-term exposure differ, if at all, from acute exposure as well as designing experiments to understand the synergistic effects of direct and indirect exposure to PM.

\section{Clinical Implications}

Research into the cardiovascular effects of PM is required in order to produce guidelines and recommendations for clinical practice. The literature, when taken as a whole, provides a useful summary of how PM can be observed in a clinical setting. First and foremost, patients at a high risk for developing acute cardiovascular events such as MI, stroke, and arrhythmias should avoid high levels of PM whenever possible. This includes both refraining from outdoor activities on days of particularly high pollution and avoiding living and working in areas prone to chronically high pollutant levels.

Secondly, the critical role of reactive oxygen species in PM-induced cardiovascular dysfunction suggests that antioxidant therapy holds some promise for the treatment of the deleterious effects of PM exposure. Antioxidant therapy would be especially appropriate in patients already at a high cardiovascular risk, or who are consistently exposed to high levels of pollutants, such as employees of industrial facilities. While increased dietary antioxidant intake has been shown to help prevent a number of diseases (Valko et al., 2007), exercise promotes the production of endogenous antioxidants (Warburton et al., 2006) in addition to its already-known benefits to cardiovascular health. On the other hand, dietary antioxidants have not yet been shown to demonstrate a clinical benefit in the treatment of cardiovascular disease. More importantly, exercise produces oxidants that may or may not be an essential whereby exercise builds redox regulation (Vollaard et al., 2005) - dietary antioxidants could interfere with this process in ways that alter the balance between exercise's proand antioxidant effects. Therefore, the literature emphasizes the importance of exercise in managing cardiovascular disease, especially in patients who may be exposed to particulate matter pollution.

Finally, antithrombotic therapy may also help prevent the onset of cardiovascular events triggered by PM-induced thrombosis. Antiplatelets may be a preventative method, as particles that enter the systemic circulation are known to promote platelet formation (Coller, 1992; Nemmar et al., 2003b). Antithrombotics should be a last resort, however, as the possible side effects of such drugs could be much more severe than the side effects of any other treatment regimen or the untreated symptoms themselves (Patrono et al., 2004).

\section{Conclusion}

A multitude of epidemiological data and clinical studies provide evidence that PM exposure causes detrimental cardiovascular dysfunction, both by direct and indirect mechanisms. These two general mechanisms can be further divided into three main pathways: direct particle entry into the vasculature, PM deposition on the alveoli (indirect), and dysfunction of the autonomic nervous system (indirect). Further research should continue to explore the effects of PM and the corresponding response pathways, specifically the nature of the effect and time course of the response. Clinicians should be aware of the consequences of exposure to PM and should continue to proactively treat this problem since the rates of industrialization are unlikely to decrease. 


\section{Highlights}

1. Air pollution affects people both directly and indirectly.

2. Direct effects involve infiltration of the endothelial lining by particulate matter, allowing direct access to the bloodstream.

3. Indirect effects of air pollution involve respiratory-mediated release of inflammatory markers and/or cytokines, which enter the bloodstream.

4. Mechanisms of direct and indirect effects of particulate matter are not entirely understood.

\section{List of Acronyms}

$\begin{array}{ll}\text { ANS } & \text { Autonomic nervous system } \\ \text { CAPs } & \text { Concentrated ambient particulates } \\ \text { CNS } & \text { Central nervous system } \\ \text { DEP } & \text { Diesel exhaust particles } \\ \text { HMMECs } & \text { Human mucosal microvascular endothelial cells } \\ \text { HNECs } & \text { Human nasal epithelial cells } \\ \text { HRV } & \text { Heart rate variability } \\ \text { ITPR2 } & \text { inositol 1,4,5-triphosphate receptor } \\ \text { MI } & \text { Myocardial infarction } \\ \text { MMP1 } & \text { Matrix metalloproteinase 1 } \\ \text { MTP } & \text { Mitochondrial permeability transition pore } \\ \text { NOS } & \text { Nitric oxide synthase } \\ \text { PM } & \text { Particulate matter } \\ \text { PM0.1, UFPs } & \text { Ultrafine particles }- \text { diameter }<0.1 \text { um } \\ \text { PM2.5 } & \text { Fine particles - diameter }<2.5 \text { um } \\ \text { PM2.5-10 } & \text { Coarse particles - diameter of 2.5-10 um } \\ \text { ROCK } & \text { Rho-associated protein kinase } \\ \text { ROS } & \text { Reactive oxygen species } \\ \text { TF } & \text { Tissue factor }\end{array}$

\section{Acknowledgments}

Sources of Funding:

This manuscript was supported in part by grants from the American Heart Association (0835298N) and the National Institutes of Health (1 R01 ES 019923-01) to LEW and a grant from the University of Notre Dame Glynn Family Honors Program (12199) to AMJ. 


\section{References}

Abramson JJ, Trimm JL, Weden L, Salam G. Heavy metals induce rapid calcium release from sarcoplasmic reticulum isolated from skeletal muscle. Proceedings of the National Academy of Science USA. 1983; 80:1526-1530.

Allen RW, Criqui MH, Diez Roux AV, Allison M, Shea S, Detrano R, Sheppard L, Wong ND, Hinckley Stukovsky K, Kaufman JD. Fine particulate matter air pollution, proximity to traffic, and aortic atherosclerosis. Epidemiology. 2009; 20:254-264. [PubMed: 19129730]

Araujo JA, Nel AE. Particulate matter and atherosclerosis: role of particle size, composition and oxidative stress. Part Fibre Toxicol. 2009; 6:24. [PubMed: 19761620]

Auchincloss A, Diez Roux A, Dvonch J, Brown P, Barr R, Daviglus M, Goff D, Kaufman J, O'Neill M. Associations between recent exposure to ambient fine particulate matter and blood pressure in the Multi-ethnic study of atherosclerosis (MESA). Environ Health Persp. 2008; 116:486-491.

Baccarelli A, Martinelli I, Zanobetti A, Grillo P, Hou L, Bertazzi PA, Mannuccio Mannucci P, Schwartz J. Exposure to particulate air pollution and risk of deep vein thrombosis. Arch Intern Med. 2008; 168:920-927. [PubMed: 18474755]

Bagate K, Meiring JJ, Cassee FR, Borm PJ. The effect of particulate matter on resistance and conductance vessels in the rat. Inhal Toxicol. 2004; 16:431-436. [PubMed: 15204758]

Bai Y, Suzuki AK, Sagai M. The cytotoxic effects of diesel exhaust particles of human pulmonary artery endothelial cells in vitro: role of active oxygen species. Free Radical Bio Med. 2001; 30:555562. [PubMed: 11182526]

Bernardi P. Mitochondrial transport of cations: channels, exchangers, and permeability transition. Physiol Rev. 1999; 79:1127-1155. [PubMed: 10508231]

Boraso A, Williams AJ. Modification of the gating of the cardiac sarcoplasmic reticulum Ca2+-release channel by H2O2 and dithiothreitol. Am J Physiol Heart Circ Physiol. 1994; 267:H1010-H1016.

Brook RD, Rajagopalan S, Pope CA, Brook JR, Bhatnagar A, Diez-Roux AV, Holguin F, Hong Y, Luepker RV, Mittleman MA, Peters A, Siscovick D, Smith SC, Whitsel L, Kaufman JD.

Particulate matter air pollution and cardiovascular disease: an update to the scientific statement from the American Heart Association. Circulation. 2010; 121:2331-2378. [PubMed: 20458016]

Carr MJ, Undem BJ. Inflammation-induced plasticity of the afferent innervation of the airways. Environ Health Persp. 2001; 109:567-571.

Cavallari J, Fang S, Eisen E, Schwartz J, Hauser R, Herrick R. Time course of heart rate variability decline following particulate matter exposures in an occupational cohort. Inhal Toxicol. 2008; 20:415-422. [PubMed: 18302049]

Chiamvimonvat N, O'Rourke B, Kamp TJ, hofmann F, Flockerzi V, Marban E. Functional consequences of sulfhydryl modification in the pore-forming subunits of cardiovascular $\mathrm{Ca} 2+$ and Na2+ channels. Circ Res. 1995; 76:325-334. [PubMed: 7859379]

Choi JH, Xu QS, Park SY, Kim JH, Hwang SS, Lee KH, Lee HJ, Hong YC. Seasonal variation of effect of air pollution on blood pressure. J Epidemiol Community Health. 2007; 61:314-318. [PubMed: 17372291]

Coetzee WA, Ichikawa H, Hearse DJ. Oxidant stress inhibits Na-Ca-exchange current in cardiac myocytes by sulfhydryl groups? Am J Physiol Heart Circ Physiol. 1994; 266:H909-H919.

Coller BS. Antiplatelet agents in the prevention and therapy of thrombosis. Annu Rev Med. 1992; 43:171-180. [PubMed: 1580582]

Davignon J, Ganz P. Role of endothelial dysfunction in atherosclerosis. Circulation. 2004; 109:III-27III-32. [PubMed: 15198963]

Donaldson K, Stone V, Seaton A, MacNee W. Ambient particle inhalation and the cardiovascular system: potential mechanisms. Environ Health Persp. 2001; 109:523-527.

Emmerechts J, Alfaro-Moreno E, Vanaudenaerde BM, Nemery B, Hoylaerts MF. Short-term exposure to particulate matter induces arterial but not venous thrombosis in healthy mice. J Thromb Haemost. 2010; 8:2651-2661. [PubMed: 21029357]

Gerlofs-Nijland ME, Boere AJF, Leseman DL, Dormans JA, Sandstrom T, Salonen RO, Bree LV, Cassee FR. Effects of particulate matter on the pulmonary and vascular system: time course in spontaneously hypertensive rats. Part Fibre Toxicol. 2005; 2:2. [PubMed: 15813961] 
Ghio A, Kim C, Devlin R. Concentrated ambient air particles induce mild pulmonary inflammation in healthy human volunteers. Am J Cardiol. 2000; 162:981-988.

Gordon T, Nadziejko C, Schlesinger R, Chen LC. Pulmonary and cardiovascular effects of acute exposure to concentrated ambient particulate matter in rats. Toxicol Lett. 1999; 96:285-288. [PubMed: 9820679]

He F, Shaffer ML, Li X, Rodriguez-Colon S, Wolbrette DL, Williams R, Cascio WE, Liao D. Individual-level PM2.5 exposure and the time course of impaired heart rate variability: the APACR Study. J Expo Sci Environ Epidemiol. 2010; 21:65-73. [PubMed: 20372190]

Ibad-Mulli A, Stieber J, Wichmann H, Koenig W, Peters A. Effect of air pollution on blood pressure: a population-based approach. Am J Public Health. 2001; 91:571-577. [PubMed: 11291368]

Ishii H, Hayashi S, Hogg J, Fujii T, Goto Y, Sakamoto N. Alveolar macrophage-epithelial cell interaction following exposure to atmospheric particles induces the release of mediators involved in monocyte mobilization and recruitment. Respir Res. 2005; 6:87. [PubMed: 16053532]

Kampa M, Castanas E. Human health effects of air pollution. Environmental Pollution. 2008; 151:362-367. [PubMed: 17646040]

Keurs, HEt; Boyden, PA. Calcium and arrhythmogenesis. Physiol Rev. 2007; 87:457-506. [PubMed: 17429038]

Louch WE, Ferrier GR, Howlett SE. Changes in excitation-contraction coupling in an isolated ventricular myocyte model of cardiac stunning. Am J Physiol Heart Circ Physiol. 2002; 283:H800-H810. [PubMed: 12124230]

Mills NL, Tornqvist H, Robinson SD, Gonzaelz M, Darnley K, MacNee W, Boon NA, Donaldson K, Blomberg A, Sandstrom T, Newby DE. Diesel Exhaust Inhalation Causes Vascular Dysfunction and Impaired Endogenous Fibrinolysis. Circulation. 2005; 112:3930-3936. [PubMed: 16365212]

Mills NL, Donaldson K, Hadoke PW, Boon NA, MacNee W, Cassee FR, Sandström T, Blomberg A, Newby DE. Adverse cardiovascular effects of air pollution. Nat Clin Pract Cardiovasc Med. 2009; 6:36-44. [PubMed: 19029991]

Morgan JP. Abnormal intracellular modulation of calcium as a major cause of cardiac contractile dysfunction. New Engl J Med. 1991; 325:625-632. [PubMed: 1861696]

Muto E, Hayashi T, Yamada K, Esaki T, Sagai M, Iguchi A. Endothelial-constitutive nitric oxide synthase exists in airways and diesel exhaust particles inhibit the effect of nitric oxide. Life Sci. 1996; 59:1563-1570. [PubMed: 8890937]

Nemmar A, Vanbilloen H, Hoylaerts MF, Hoet PHM, Verbruggen A, Nemery B. Passage of Intratracheally Instilled Ultrafine Particles from the Lung into the Systemic Circulation in Hamster. Am J Resp Crit Care. 2001; 164:1665-1668.

Nemmar A, Hoet PHM, Vanquickenborne B, Dinsdale D, Thomeer M, Hoylaerts MF, Vanbilloen H, Mortelmans L, Nemery B. Passage of inhaled particles into the blood circulation in humans. Circulation. 2002; 105:411. [PubMed: 11815420]

Nemmar A, Hoylaerts MF, Hoet PH, Vermylen J, Nemery B. Size effect of intratracheally instilled particles on pulmonary inflammation and vascular thrombosis. Toxicol Appl Pharmacol. 2003a; 186:38-45. [PubMed: 12583991]

Nemmar A, Hoet PH, Dinsdale D, Vermylen J, Hoylaerts MF, Nemery B. Diesel exhaust particles in lung acutely enhance experimental peripheral thrombosis. Circulation. 2003b; 107:1202-1208. [PubMed: 12615802]

Okayama Y, Kuwuhara M, Suzuki AK, Tsubone H. Role of ractive oxygen species on diesel exhaust particle-induced cytotoxicity in rat cardiac myocytes. J Toxicol Env Health. 2006; 69:1699-1710.

Patrono C, Coller B, FitzGerald GA, Hirsh J, Roth G. Platelet-active drugs: the relationships among dose, effectiveness, and side effects: the seventh ACCP conference on antithrombotic and thrombolytic therapy. Chest. 2004; 126:2345-2345.

Peters A, Dockery DW, Muller JE, Mittleman MA. Increased particulate air pollution and the triggering of myocardial infarction. Circulation. 2001; 103:2810-2815. [PubMed: 11401937]

Pope CA, Burnett RT, Thurston GD, Thun MJ, Calle EE, Krewski D, Godleski JJ. Cardiovascular mortality and long-term exposure to particulate air pollution: epidemiological evidence of general pathophysiological pathways of disease. Circulation. 2004; 109:71-77. [PubMed: 14676145] 
Pope C III, Verrier R, Schwartz J, Gold DR, Mittleman M, Baliff J, Oh J, Allen G, Monahan K, Dockery D. Heart rate variability associated with particulate air pollution. Am Heart J. 2000; 138:890-899. [PubMed: 10539820]

Puett RC, Hart JE, Yanosky JD, Paciorek C, Schwartz J, Suh H, Speizer FE, Laden F. Chronic fine and coarse particulate exposure, mortality, and coronary heart disease in the nurses' health study. Environ Health Perspect. 2009; 117:1702-1706. [PubMed: 20049119]

Scharrer E, Hessel H, Kronseder A, Guth W, Rolinski B, Jorres R, Radon K, Schierl R, Angerer P, Nowak D. Heart rate variability, hemostatic and acute inflammatory blood parameters in helathy adults after short-termexposure to welding fume. Int Arch Occup Environ Health. 2007; 80:265272. [PubMed: 16791613]

Seaton A, MacNee W, Donaldson K, Godden D. Particulate air pollution and acute health effects. Lancet. 1995; 345:176-178. [PubMed: 7741860]

Shimada A, Kawamura N, Okajima M, Kaewamatawong T, Inoue H, Morita T. Translocation pathway of the intratracheally instilled ultrafine particles from the lung into the blood circulation in the mouse. Toxicol Pathol. 2006; 34:949-957. [PubMed: 17178695]

Simkhovich BZ, Kleinman MT, Kloner RA. Particulate air pollution and coronary heart disease. Curr Opin Cardiol. 2009; 24:604-609. [PubMed: 19696664]

Sullivan J, Sheppard L, Schreuder A, Ishikawa N, Siscovick D, Kaufman J. Relation between shortterm fine-particulate matter exposure and onset of myocardial infarction. Epidemiology. 2005; 16:41-48. [PubMed: 15613944]

Shimokawa H, Takeshita A. Rho-kinase is an important therapeutic target in cardiovascular medicine. Arterioscler. Thromb Vasc Biol. 2005; 25:1767-1775. [PubMed: 16002741]

Sun Q, Yue P, Ying Z, Cardounel A, Brook R, Devlin R, Hwang J, Zweier J, Chen L, Rajagopalan S. Air pollution exposure potentiates hypertension through reactive oxygen species-mediated activation of hypertension through reactive oxygen species-mediated activation of Rho/ROCK. Arterioscler Thromb Vasc Biol. 2008a; 28:1760-1766. [PubMed: 18599801]

Sun Q, Yue P, Kirk RI, Wang A, Moatti D, Jin X, Lu B, Schecter AD, Lippmann M, Gordon T, Chen LC, Rajagopalan S. Ambient air particulate matter exposure and tissue factor expression in atherosclerosis. Inhal Toxicol. 2008b; 20:127-137. [PubMed: 18236227]

Sun Q, Hong X, Wold LE. Cardiovascular effects of ambient particulate air pollution. Circulation. 2010; 121:2755-2765. [PubMed: 20585020]

Suwa T, Hogg J, Quinlan K, Ohgami A, Vincent R, van Eeden S. Particulate air pollution induces progression of atherosclerosis. J Am Coll Cardiol. 2002; 39:935-942. [PubMed: 11897432]

Tamagawa E, Bai N, Morimoto K, Gray C, Mui T, Yatera K, Zhang X, Xing L, Li Y, Laher I, Sin DD, Man SF, van Eeden SF. Particulate matter exposure induces persistent lung inflammation and endothelial dysfunction. Am J Physiol Lung Cell Mol Physiol. 2008; 295:L79-L85. [PubMed: 18469117]

Terada N, Hamano N, Maesako KI, Hiruma K, Hohki G, Suzuki K. Diesel exhaust particulates upregulate histamine receptor mRNA and increase histamine-induced IL-8 and GM-CSF production in nasal epithelial cells and endothelial cells. Clin Exp Allergy. 1999; 29:52-59. [PubMed: 10051702]

Tofler GH, Muller JE. Triggering of acute cardiovascular disease and potential preventive strategies. Circulation. 2006; 114:1863-1872. [PubMed: 17060396]

Valko M, Leibfritz D, Moncol J, Cronin MTD, Mazur M, Telser J. Free radicals and antioxidants in normal physiological function and human disease. Int J Biochem Cell Biol. 2007; 39:44-84. [PubMed: 16978905]

Van Eeden S, Tan WC, Suwa T, Mukae H, Terashima T, Fujii t, Qui D, Vincent R, Hogg J. Cytokines involved in the systemic inflammatory response induced by exposure to particulate matter air pollutants (PM 10). Am J Resp Crit Care. 2001; 164:826-830.

Vermylen J, Nemmar A, Nemery B, Hoylaerts MF. Ambient air pollution and acute myocardial infarction. J Thromb Haemost. 2005; 3:1955-1961. [PubMed: 16102102]

Vollaard NB, Shearman JP, Cooper CE. Exercise-induced oxidative stress: myths, realities and physiological relevance. Sports Med. 2005; 35:1045-1062. [PubMed: 16336008] 
Warburton DER, Nicol CW, Bredin SSD. Health benefits of physical activity: the evidence. Can Med Assoc J. 2006; 174:801-809. [PubMed: 16534088]

Watkinson W, Campen MJ, Nolan JP, Costa DL. Cardiovascular and systemic responses to inhaled pollutants in rodents; effects of ozone and particulate matter. Environ Health Persp. 2001; 109:539-546.

Whitsel EA, Quibrera PM, Christ SL, Liao D, Prineas RJ, Anderson GL, Heiss G. Heart rate variability, ambient particualte matter air pollution, and glucose homeostasis: the environmental epidemiology of arrhythmogenesis in the women's health initiative. Am J Epidemiol. 2009; 169:693-703. [PubMed: 19208727]

Wilker E, Mittleman M, Litonjua A, Poon A, Baccarelli A, Suh H, Wright R, Sparrow D, Vokonas P, Schwartz J. Postural changes in blood pressure associated with interactions between candidate genes for chronic respiratory diseases and exposure to particulate matter. Environ Health Persp. 2009; 117:935-940.

Wold LE, Simkhovich BZ, Kleinman MT, Nordlie MA, Dow JS, Sioutas C, Kloner RA. In vivo and in vitro models to test the hypothesis of particle-induced effects on cardiac function and arrhythmias. Cardiovasc Toxicol. 2006; 6:69-78. [PubMed: 16845184]

Xia T, Korge P, Weiss JN, Li N, Venkatesen MI, Sioutas C, Nel A. Quinones and aromatic chemical compounds in particulate matter induce mitochondrial dysfunction: implications for ultrafine particle toxicity. Environ Health Persp. 2004; 112:1347-1358.

Yarnell J, McCrum E, Rumpley A, Patterson C, Salomaa V, Lowe G. Association of European population levels of thrombotic and inflammatory factors with risk of coronary heart disease: the MONICA Optional Haemostasis Study. Eur Heart J. 2005; 26:332-342. [PubMed: 15618045]

Yergey JA, Risby TH. Chemical characterization of organic adsorbates on diesel particulate matter. Anal Chem. 1982; 54:354-357.

Yusuf S, Reddy S, Ounpuu S. Global burden of cardiovascular diseases. Part I: General considerations, the epidemiologic transition, risk factors, and impact of urbanization. Circulation. 2001; 104:2746-2753. [PubMed: 11723030]

Zuo L, Youtz DJ, Wold LE. Particulate matter exposure exacerbates high glucose-induced cardiomyocyte dysfunction through ROS generation. PLoS ONE. 2011; 6:e23116. [PubMed: 21850256] 


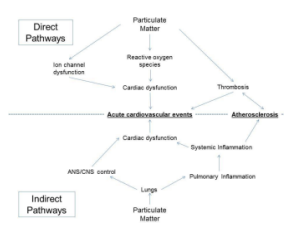

Figure 1.

Summary of the pathways by which particulate matter promotes acute cardiovascular events and atherosclerosis. Mechanisms can be broadly divided into direct and indirect pathways. 
Table 1

Summary of the direct and indirect effects of particulate matter on the cardiovascular system.

\begin{tabular}{|c|c|c|}
\hline Pathway & Mechanism & References \\
\hline \multirow[t]{3}{*}{ Indirect } & ANS/CNS Alteration & $\begin{array}{l}\text { Ibad-Mulli et al., } 2001 \\
\text { Wilker et al., } 2009 \\
\text { Auchincloss et al., } 2008 \\
\text { Gordon et al., } 1999 \\
\text { Sun et al., 2008a } \\
\text { Suwa et al., } 2002\end{array}$ \\
\hline & Rho/ROCK Dysfunction & $\begin{array}{l}\text { Sun et al., 2008a } \\
\text { Shimokawa et al., } 2005\end{array}$ \\
\hline & Systemic Inflammation & Terada et al., 1999 \\
\hline \multirow[t]{2}{*}{ Indirect and Direct } & Inflammation & $\begin{array}{l}\text { Yarnell et al., } 2005 \\
\text { Ghio et al., } 2000 \\
\text { Van Eeden et al., } 2001 \\
\text { Ishii et al., } 2005 \\
\text { Cavallari et al., } 2008 \\
\text { Gerlofs-Nijland et al., } 2005\end{array}$ \\
\hline & Thrombosis & $\begin{array}{l}\text { Nemmar et al., 2003a } \\
\text { Nemmar et al., 2003b }\end{array}$ \\
\hline \multirow{3}{*}{ Direct } & Reactive Oxygen Species & $\begin{array}{l}\text { Zuo et al., } 2011 \\
\text { Yergey and Risby, } 1982 \\
\text { Donaldson et al., } 2001\end{array}$ \\
\hline & Ion Channel Dysfunction & $\begin{array}{l}\text { Coetzee et al., } 1994 \\
\text { Chiamvimonvat et al., } 1995 \\
\text { Abramson, et al., } 1983 \\
\text { Xia et al., } 2004 \\
\text { Bernardi et al., } 1999\end{array}$ \\
\hline & Vascular Dysfunction & $\begin{array}{l}\text { Nemmar et al., 2003a } \\
\text { Nemmar et al., 2003b } \\
\text { Vermylen et al., } 2005\end{array}$ \\
\hline
\end{tabular}

